\title{
Ruby Laser Interaction with Austenite Structural Materials
}

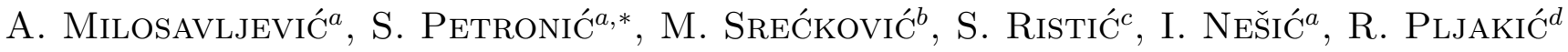 \\ AND V. NEgOVANOVić ${ }^{b}$ \\ ${ }^{a}$ Faculty of Mechanical Engineering, University of Belgrade, Kraljice Marije 16, 11120 Belgrade, Serbia \\ ${ }^{b}$ Faculty of Electrical Engineering, University of Belgrade, Bulevar Kralja Aleksandra 73, 11120 Belgrade, Serbia \\ ${ }^{c}$ Goša Institute, Milana Rakica 54, 11000 Belgrade, Serbia \\ d "Prva Petoletka" AD, Cara Dusana 101, 37240 Trstenik, Serbia
}

\begin{abstract}
The investigations were carried out on chrome nickel steel and nickel based superalloy samples thermo-mechanically treated to obtain optimal mechanical properties and surface stability. Chrome nickel steel and a few nickel based superalloys samples were exposed to the laser beam before creep deformation process. The second group of nickel based superalloy samples were exposed after the creep deformation. The damages occurred by exposing of chrome nickel steel and nickel base superalloy samples to the ruby laser were analyzed by scanning electron microscope and energy-dispersive X-ray spectrometry. In this paper, the influence of laser dynamical regime $\left(\mathrm{MW} / \mathrm{mm}^{2}\right)$ to the microstructural changes of heat treated chrome nickel steel and nickel based superalloy are analyzed and discussed.
\end{abstract}

PACS numbers: 01.55.+b 42.62.-b, 81.05.-t

\section{Introduction}

Austenitic materials are widely used in advanced technical applications. Recently, much interest has been focused on the designing of new generation nickel based superalloys with excellent mechanical properties in order to satisfy severe demands in nuclear energy applications. The ultrasupercritical steam power projects may require nickel based alloys in superheaters, piping systems and turbine components. Several of the generation IV nuclear power projects may require nickel based superalloys for core support components, piping systems, heat exchangers, and gas turbines [1].

Good physical and mechanical properties, surface stability at elevated temperature, pressure and aggressive environment, nickel based superalloys owe to their atomic and electronic structures [2-4]. A very good ability of alloying elements dissolution in nickel lattice is affected by: nickel lattice parameter, atomic diameter and a number of electrons in the last sheath electron.

Nickel based superalloys among all other materials possess the most complex structure formed through advanced melting and refining technologies, and strengthening face centered cubic (fcc) nickel matrix by dozen alloying elements and post-heat treating. Saturated solution is formed by solution treating and after additional heat treatments various secondary phases (carbides, oxides and topologically closed-packed (TCP) unwanted phases) start to precipitate.

* corresponding author; e-mail: sanjapetronic@yahoo.com
Depending on temperature and duration of heat treatment and exploitation of nickel based superalloys, various phase transformations can occur as a consequence of phase instability. The phase instability can essentially affect the following physical properties: specific heat capacity, thermal conductivity, coefficient of thermal expansion, density, electrical resistivity etc. However, if chemical composition of superalloy is not carefully controlled, during the heat treatment, and especially during exploitation at elevated temperature TCP phases may segregate which are harmful to the superalloy's mechanical properties. The most common unwanted TCP phase in nickel base superalloy is $\sigma$ phase with tetragonal lattice and formula $(\mathrm{Fe}, \mathrm{Mo})_{x}(\mathrm{Ni}, \mathrm{Co})_{y}$, where $x$ and $y$ can vary from 1 to $7[5]$.

In order to satisfy the high requirements regarding to physical, mechanical properties and surface stability of stated alloys and to avoid formation of unwanted TCP phase structures, the heat treatments in vacuum and advanced laser techniques such as laser alloying, surface treatment and welding are widely used.

\section{Experimental}

Chrome nickel steel and nickel base superalloy samples were heat treated in vacuum $[6,7]$ and the chemical compositions were obtained by wet method.

Tensile strength tests were carried out to determine yield strength, tensile strength and elongation. Tensile tests were performed by electromechanical testing machine SCHENCK TREBEL RM 400. Chemical compositions are listed in Table I and mechanical properties are listed in Table II. 
TABLE I

Chemical composition of alloy 1 and alloy 2 .

\begin{tabular}{l|c|c|c|c|c|c|c|c|c|c}
\hline \hline $\begin{array}{c}\text { Element } \\
\text { Alloy }\end{array}$ & $\mathrm{Ni}$ & $\mathrm{Cr}$ & $\mathrm{Mo}$ & $\mathrm{Mn}$ & $\mathrm{Si}$ & $\mathrm{Fe}$ & $\mathrm{C}$ & $\mathrm{Al}$ & $\mathrm{Co}$ & $\mathrm{W}$ \\
\hline $\begin{array}{l}\text { alloy 1 (A1) } \\
\text { alloy 2 (A2) }\end{array}$ & 19.06 & 24.11 & 0.23 & 1.53 & 1.66 & 53.43 & 0.6 & $/$ & $/$ & $/$ \\
& 19.8 & 9 & 0.2 & 0.8 & 20.5 & 0.2 & 0.2 & 1.5 & 0.6
\end{tabular}

TABLE II

Mechanical properties of alloy 1 and alloy 2 .

\begin{tabular}{c|c|c|c}
\hline \hline $\begin{array}{c}\text { Mechanical } \\
\text { properties }\end{array}$ & $\begin{array}{c}R_{0.2} \\
{\left[\mathrm{~N} / \mathrm{mm}^{2}\right]}\end{array}$ & $\begin{array}{c}R_{\mathrm{m}} \\
{\left[\mathrm{N} / \mathrm{mm}^{2}\right]}\end{array}$ & $\begin{array}{c}A_{5} \\
{[\%]}\end{array}$ \\
\hline \multirow{3}{*}{ alloy 1 (A1) } & 334 & 609 & 51.4 \\
& 337 & 617 & 52.8 \\
& 342 & 620 & 57 \\
\hline \multirow{3}{*}{ alloy 2 (A2) } & 360 & 770 & 43 \\
& 368 & 781 & 41 \\
& 369 & 783 & 44
\end{tabular}

Austenite steel and multicomponent nickel superalloys were exposed to pulsed ruby laser-Apollo in Q-switch mode. The ruby laser operating characteristics were: pulse duration - $30 \mathrm{~ns}$, wavelength $-694.3 \mathrm{~nm}$, coherent beam length $-1 \mathrm{~m}$ and focal lens length $-100 \mathrm{~mm}$. The focus beam and various positions of samples placed to the lens were used. Laser was adjusted to work with $1 \mathrm{~J}$ output energy; thereby the laser power was $\approx 30 \mathrm{MW}$, with two pulses applied to the every point.

Ruby laser beam was applied to three samples of chrome nickel steel, and six samples of nickel based superalloy. Investigations and observation were carried out at the samples before and after creep deformation process.

The crater shaped defects were observed by scanning electronic microscope (SEM). Using energy-dispersive X-ray spectrometry (EDS), some of damages arisen by interaction of material with ruby laser were analyzed.

\section{Results and discussion}

According to results of investigation carried out on alloy A1 and alloy A2, showed in Table I and Table II can be concluded that previous heat treatments produced good mechanical properties. The high content of nickel contributed to $\gamma$ matrix stability, and high chrome content to strengthening and increase in corrosion resistance.

Micrograph in Fig. 1 shows an irregular shaped damage arisen by interaction of ruby laser and alloy A1. EDS analysis showed in Table III reveals dominant presence of $\mathrm{Fe}, \mathrm{Ni}, \mathrm{Cr}$.

The speculated results of elements volume fraction taken at the point 1 and the point 2, indicated in Fig. 1, and comparing nominal composition listed in Table I with the compositions given in Table III, point to the inhomogeneous chemical elements distribution arisen by laser

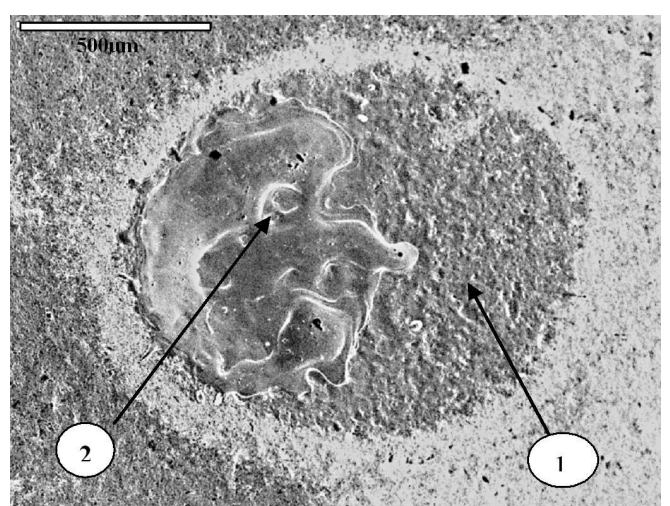

Fig. 1. SEM micrograph of alloy 1 after exposition to the ruby laser (2 pulses of $1 \mathrm{~J}, 30 \mathrm{~ns}$ ).

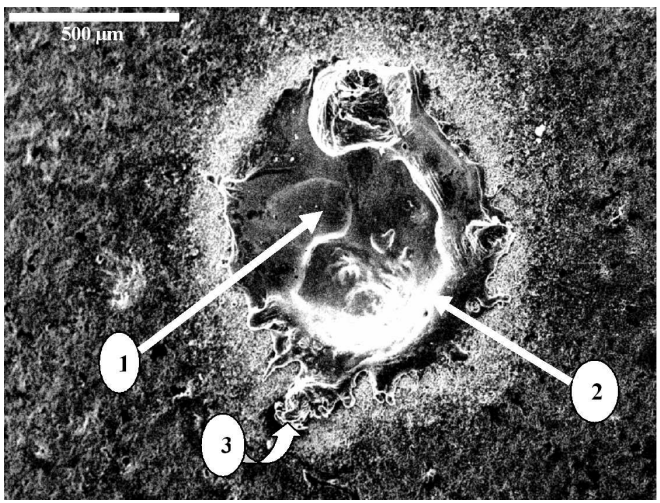

Fig. 2. SEM micrograph of alloy 2 after exposition to the ruby laser ( 2 pulses of $1 \mathrm{~J}, 30 \mathrm{~ns}$ ) before creep process.

beam interaction with materials. Increased content of $\mathrm{Cr}$ may indicate possible carbides presence at point 1 and at point 2. As Mn and Si promote carbide forming, their increased content indicates carbide presence as well.

Laser beam interaction with alloy A2 results in damage showed in Fig. 2. The micrograph of damaged area

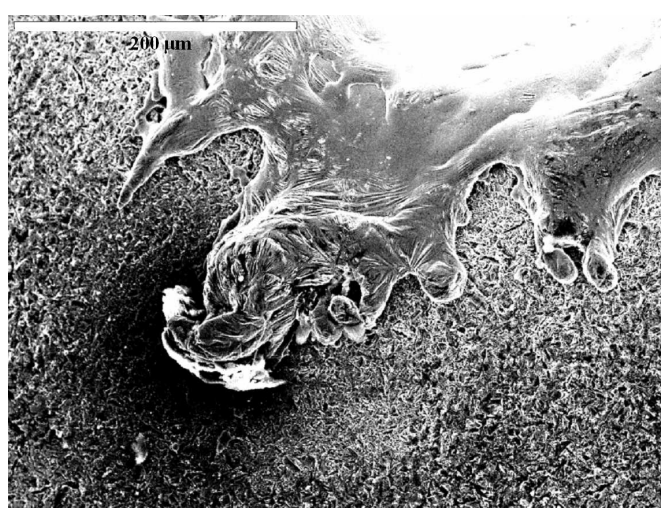

Fig. 3. Detail 3 indicated in Fig. 2. 


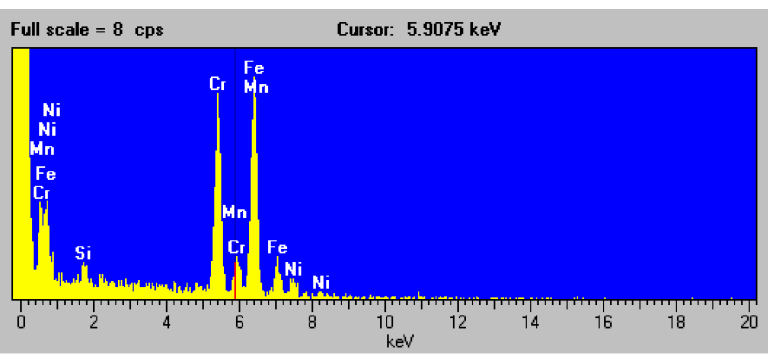

Fig. 4. EDS pattern for the results listed in Table IV taken from Fig. 2 at point 1.

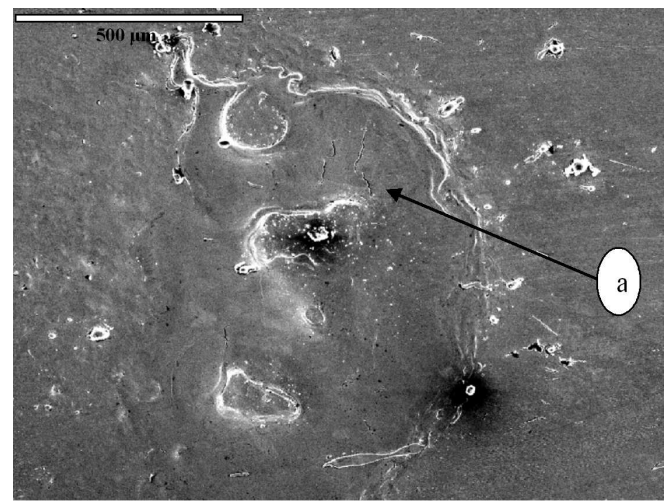

Fig. 5. SEM micrograph of alloy 2 after exposition to the ruby laser (2 pulses of $1 \mathrm{~J}, 30 \mathrm{~ns}$ ) after the creep process.

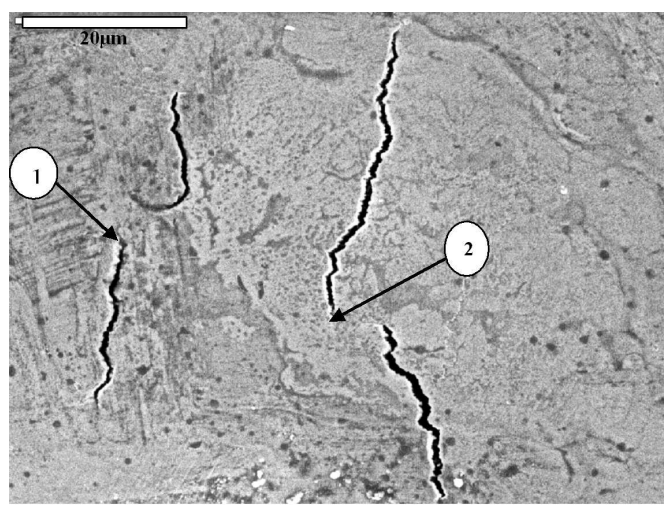

Fig. 6. Detail "a" indicated in Fig. 5.

\section{TABLE III}

Typical composition of the marked regions in Fig. 1 determined by EDS.

\begin{tabular}{c|c|c|c|c|c}
\hline \hline Element & $\mathrm{Si}$ & $\mathrm{Cr}$ & $\mathrm{Mn}$ & $\mathrm{Fe}$ & $\mathrm{Ni}$ \\
\hline $\begin{array}{l}\text { \% mass } \\
\text { point 1 }\end{array}$ & 1.913 & 1.36 & 4.45 & 55.65 & 6.62 \\
\hline $\begin{array}{l}\text { \% mass } \\
\text { point 2 }\end{array}$ & 1.27 & 32.56 & 2.03 & 56.11 & 7.03
\end{tabular}

TABLE IV

Typical composition of the marked regions in Fig. 2 determined by EDS.

\begin{tabular}{c|c|c|c|c|c|c|c|c}
\hline \hline Element & $\mathrm{Al}$ & $\mathrm{Si}$ & $\mathrm{Cr}$ & $\mathrm{Mn}$ & $\mathrm{Fe}$ & $\mathrm{Co}$ & $\mathrm{Ni}$ & $\mathrm{Mo}$ \\
\hline $\begin{array}{l}\% \text { mass } \\
\text { point 1 }\end{array}$ & 0.17 & 0.60 & 18.93 & 0.89 & 17.61 & 1.66 & 53.05 & 7.09 \\
\hline $\begin{array}{l}\% \text { mass } \\
\text { point 2 }\end{array}$ & 0.18 & 0.67 & 19.13 & 0.65 & 17.91 & 1.71 & 52.98 & 6.76 \\
\hline $\begin{array}{l}\% \text { mass } \\
\text { point 3 }\end{array}$ & 0.70 & 1.35 & 18.98 & 0.82 & 17.57 & 1.94 & 50.27 & 8.37
\end{tabular}

TABLE V

Typical composition of the marked regions in Fig. 6 determined by EDS.

\begin{tabular}{c|c|c|c|c|c|c|c|c|c}
\hline \hline Element & $\mathrm{Al}$ & $\mathrm{Si}$ & $\mathrm{S}$ & $\mathrm{Cr}$ & $\mathrm{Mn}$ & $\mathrm{Fe}$ & $\mathrm{Co}$ & $\mathrm{Ni}$ & $\mathrm{Mo}$ \\
\hline $\begin{array}{l}\% \text { mass } \\
\text { point 1 }\end{array}$ & 0.19 & 0.73 & 1.52 & 19.53 & 0.89 & 17.95 & 1.84 & 50.12 & 7.22 \\
\hline $\begin{array}{l}\text { \% mass } \\
\text { point 2 }\end{array}$ & 0.32 & 0.73 & 1.19 & 19.32 & 0.94 & 18.18 & 1.75 & 50.07 & 8.51
\end{tabular}

indicates spattering of material due to very high cooling rates. Figure 3 shows the detail taken from Fig. 2, that came of the central part of the sample.

Figure 4 and Table IV show SEM and EDS analyses taken from Fig. 2 at the point 1. It is noticeable dominant content of $\mathrm{Ni}, \mathrm{Fe}, \mathrm{Cr}$, Mo.

Exposition of the sample, cut out of the aeromachine combustion liner after $40000 \mathrm{~h}$ exploitation at temperature higher than $700^{\circ} \mathrm{C}$, to the ruby laser beam resulted in the damage presented in Fig. 5. The damaged area is irregularly shaped with spattering. There are cracks noticed in Fig. 5, and they can be clearer observed in Fig. 6. Cracks appearance in the material of alloy A2, obtained by material exposition to the laser beam and the creep deformation process, certainly is result of high laser power density applied, but effect of structural transformation after creep process is significant as well and should not be neglected.

There are two well accepted theories in literature $[5,8-10]$ about superalloys carbides cracks initiation. According to the first theory [8], during the process of creep deformation, carbides $\mathrm{M}_{23} \mathrm{C}_{6}$ and unwanted TCP- $\sigma$ phases represent the place where cracks initiate due to the carbide segregation at the grain boundaries. It is considered [9] that $\mathrm{Cr}$ forms $\mathrm{M}_{23} \mathrm{C}_{6}$ carbides which precipitate along the grain boundaries on dislocations; they are platelets and harmful for the microstructure. During the creep deformation process, they coarsen along the grain boundaries, and $\gamma$-matrix depletes in $\mathrm{Cr}$.

Table V, based on our results and investigations, shows chemical compositions at the points 1 and 2 in Fig. 6 . EDS analysis gives evidence about higher content of $\mathrm{Ni}$, Mo, Co and suggests a possibility of TCP- $\sigma$ phases formation. This statement is substantiated in litera- 
ture [11]. There is presence of $\mathrm{S}$ as well, but we consider that $\mathrm{Mn}$, through bonding $\mathrm{S}$ in compound $\mathrm{MnS}$, annuls detrimental effect of sulfur.

We consider that the carbides coarsening took place during the creep deformation process and helped by the increased content of $\mathrm{Si}$ carbides became the places for TCP phase formation. Literature [12] consist data that Si promotes TCP phase formation 3 times more than $\mathrm{Cr}$.

The increased diffusion $\mathrm{Mo}, \mathrm{Ni}, \mathrm{Co}, \mathrm{Fe}$ atoms was induced by high heat temperature. The high temperature promotes the $\sigma$-phase forming with complex crystal structure non-coherent with the $\gamma$-base.

It is well known that TCP phases segregate in needle morphological shape along carbides grain boundaries, and parallel to the $\{1,1,1\} \gamma$-matrix plane. We consider that bcc elements (such as W, Cr and Mo) present in $\sigma$ phase affect morphological shape. We consider that, by controlling chemical composition and vacuum heat treatment, formation of TCP phases was successfully avoided and they were not identified even after creep deformation process. At the samples that were exposed to laser beam before creep deformation the cracks were not identified. However, the samples that were exploited suffered from cracks.

\section{Conclusion}

Based on listed reference data, our previous investigations and experimental results carried out at chrome nickel steel and nickel based superalloys can be concluded:

- After applying ruby laser beam to alloy materials before creep deformation process the cracks were not identified;

- After applying ruby laser beam to alloy materials after creep deformation process the cracks were identified

- The irregular shape of damages and the crack occurrence were produced by high laser beam power;
- The cracks formation was affected by structural degradation of material after the creep deformation process;

- The high percent of the bcc elements that promote or form morphologically unfavorable carbides and TCP phases were detected by SEM and EDS;

- TCP phases, formed during the creep deformation process, and $\gamma$ matrix have different coefficient of thermal expansion, and this phenomenon leads to the residual structural stress generation.

\section{References}

[1] R.W. Swindeman, M.J. Swindeman, Int. J. Pressure Vessels Piping 85, 72 (2008).

[2] R.C. Reed, The Superalloys, Fundamentals and Applications, Cambridge University Press, New York 2006.

[3] The Superalloys, Wiley, New York 1972.

[4] Z. Thao, W. Chong-Yu, Chin. Phys. 15, 2087 (2006).

[5] Metal Handbook, Vol. 1, Properties and Selection: Iron, Steel, and High-Perf. Alloys, 10th ed., ASMI, Materials Park, Ohio, 2005.

[6] A. Milosavljevic, M. Sreckovic, S. Bojanic, M. Dinulovic, B. Ljubisavljevic, Vacuum 47, 1413 (1996).

[7] S. Petronic, A. Milosavljevic, FME Trans. 35, 4 (2007).

[8] L.Z. He, Q. Zheng, X.F. Sun, H.R. Guan, Z.Q. Hu, A.K. Tieu, C. Lu, H.T. Zhu, Mater. Sci. Eng. A 397, 297 (2005).

[9] L.R. Lui, T. Jin, N.R. Zhao, X.F. Sun, H.R. Guan, Z.Q. Hu, Mater. Sci. Eng. A 361, 191 (2003).

[10] J. Yang, Rare Metals 25, 202 (2006).

[11] E. Pocuca, M.Sc. Thesis, University of Belgrade, 2004.

[12] Overhaul Standard Practical Manual, Vol. 2, Pratt and Whithey, UTC, United States 2003, p. 113. 